\title{
Public acceptability of indirect potable water reuse in the south-east of England
}

\author{
Victoria Aitken ${ }^{1}$, Sarah Bell ${ }^{2}$, Sian Hills ${ }^{3}$ and Lucy Rees ${ }^{2}$ \\ ${ }^{1}$ Curtin University, Perth, Western Australia, vaitkin@mac.com \\ ${ }^{2}$ Civil, Environmental and Geomatic Engineering, University College London, Gower St, \\ London WC1E 6BT, United Kingdom s.bell@ucl.ac.uk (corresponding author) \\ ${ }^{3}$ Thames Water Utilities Ltd, Reading, United Kingdom, sian.hills@ hotmail.co.uk
}

\section{Keywords}

Water reuse, public perception, surveys, demographic factors

\begin{abstract}
Public controversy over planned indirect potable reuse of wastewater has been a significant obstacle to implementing proposed schemes in the United States and Australia. Surveys of public attitudes to water reuse have generally shown lower acceptance of indirect potable reuse compared with other reuse options, such as irrigation. The south-east of England is projected to experience a shortfall in water supply by 2020 and the largest water utility in the region, Thames Water, is investigating indirect potable reuse as a potential new supply option. The indirect potable reuse feasibility studies include evaluation of the technology options and water quality as well as detailed consideration of public perception issues. As part of the work to address the latter, 2,000 Thames Water customers participated in an online survey of their attitudes to indirect potable reuse. The survey showed overall support for the idea of indirect potable reuse. The only demographic factor to show any significant difference from the whole sample was belief system, with Muslim respondents showing significantly less support than other groups. The survey results indicate that indirect potable reuse may be socially acceptable in the south-east of England, but that public engagement and participation in future decision making about indirect potable reuse will be important for the success of any particular proposal.
\end{abstract}




\section{Public acceptability of indirect potable water reuse in the south-east of England}

\section{Introduction}

Water reuse is an increasingly important option for ensuring the sustainability of urban water systems. Public acceptability is widely acknowledged to be a key factor in determining the success of water reuse schemes. Proposals for indirect potable reuse have been particularly controversial and public opposition has disrupted the implementation of these type of reuse schemes in the United States and Australia (Hurlimann and Dolnicar, 2010; Shipps, 2013).

The south-east of England, including London, is a water scarce region, presenting serious challenges for urban planners and water managers in the coming decades. Conventional water sources such as rivers and ground water in the region are close to or have exceeded ecologically sustainable levels of abstraction. In the south-east region as whole, the most severe predictions show a baseline overall deficit of 856,000 cubic metres per day in water supply by 2040 (Water Resources in the South East Group, 2013). Thames Water Utilities Ltd (Thames Water) is the largest water and wastewater supply company in England. Thames Water supplies drinking water to nine million customers in the south-east region. In their supply area annual rainfall is approximately 700 millimetres and average per capita domestic consumption is currently 161 litres per person per day. Per capita consumption is projected to remain at this level, with potential population increases of 1.5 to 2.3 million people by 2040 . Thames Water predicts that demand will outstrip supply by 2020, with a 260,000 cubic metres per day shortfall by 2040. Indirect potable reuse of water is one option for securing future water supplies being considered by the company. Public acceptability is a key area of research as part of a broader feasibility study of indirect potable reuse in to supply London (Thames Water, 2013).

Planned water reuse is not widely practiced in the United Kingdom. However, treated wastewater is an important component of river flows, especially in south-east England. As most catchments in this region are highly urbanised this results in unplanned reuse, as water treatment works further downstream abstract from rivers receiving wastewater from upstream towns and cities. There is also one planned indirect potable reuse scheme in operation. The Langford recycling scheme owned by Essex and Suffolk Water discharges reclaimed water into the River Chelmer, allowing higher abstractions further downstream into a reservoir prior to treatment for potable use (Angelakis and Durham, 2008).

Effective public engagement is essential for good decision making regarding water reuse proposals (Hartley, 2006). Surveys of public acceptability are a good first step in evaluating the feasibility of reuse and provide useful baseline data from which to design effective public engagement programmes. Surveys can be used to highlight general levels of support or opposition to water reuse, areas of concern to members of the public and any differences between demographic groups, which can help to inform public engagement strategies.

Public acceptability and public engagement were key components of a study of the feasibility of indirect potable reuse in London. The aims of the social research component of the feasibility study were to:

- identify social factors that could undermine the feasibility of indirect potable reuse in London, 
- determine the extent to which international experience in the public acceptability of indirect potable reuse is relevant in the United Kingdom context, and

- provide baseline data to guide strategies for public engagement with any future proposal for implementation of indirect potable reuse in London

The social research programme consisted of a review of international experience, surveys of public acceptability, and deliberative forum.

This paper presents the results of an on-line survey of 2,000 Thames Water customers regarding the acceptability of indirect potable reuse. The aims of the survey were to:

1. determine the baseline levels of acceptability in the London and Thames Valley population;

2. identify demographic factors which influence levels of acceptability; and

3. compare the United Kingdom results with previous international studies.

The paper begins with a review of factors influencing public acceptability of water reuse and summarises previous surveys from different countries. It outlines the methodology used in the Thames Water on-line survey, discusses the most significant findings, and concludes by comparing the Thames Water results with international studies, outlining the implications of survey results for future public engagement strategies.

\section{Social factors in water reuse}

Public acceptability is well established as a key factor in the success of water reuse schemes. Public acceptability has been shown to depend upon the proposed use of recycled water, the level of prior experience and knowledge of water reuse, the perceived risk of serious water shortages, and a small number of demographic variables (Dolnicar et al., 2010; 2011). Public acceptability can be positively and negatively influenced by communication strategies, public consultation and engagement, and public involvement in decision making (Bell and Aitken, 2008; Colebatch, 2006; Dolnicar et al., 2010; Hurlimann and Dolnicar, 2010).

Traditional approaches to the feasibility and implementation of water reuse have been criticised for reliance on technological solutions, to the exclusion of social factors (Bell and Aitken, 2008). Pioneering studies by Bruvold (1985; 1988; 1992) first noted negative public attitudes towards reuse. Although decades of research have produced numerous studies assessing individual factors behind public acceptance, few collate these. Within reuse literature there is therefore a call for comprehensive social appraisals to be included within the initial steps of a reuse network project (Po et al., 2003). Illemobade et al (2009) confirm although many projects identify social perceptions as an issue, approaches to counter this mainly centre upon incentivising attitudinal change. This has been associated with the "deficit model" of science communication (Bell and Aitken, 2008), whereby community objection is often blamed upon a lack of understanding of reuse technologies and water resource management, without analysis of social and cultural context.

A few notable studies have attempted to assemble a range of social factors with influence over reuse project success. Hartley (2003; 2006), Po et al. (2003), Dolnicar and Hurliman (2010) and Dolnicar et al. (2011) provide the most comprehensive reviews, summarising seven key factors.

1. The 'source factor'

Public perception of the source of water and its "use history" is highlighted as important across the literature (Po et al., 2003, p.20). According to Hartley (2003) and Po et al. (2003), 
people are more likely to accept reuse of water from their own home over a public source. This relates to the "yuck factor", noted across the literature (Jeffry, 2002; Hartley, 2003; Bell and Aitken, 2008). This refers to emotional responses to the idea of using recycled water, including disgust at the perception of proximity to 'waste' (Po et al., 2003). This has been cited as a key factor in the rejection of a number of reuse schemes globally in the 1990s, where terms such as "toilet to tap" and "sewerage beverage" pervaded media coverage of proposals in the United States (Hartley, 2003).

\section{End use}

The proposed end-use of recycled water is widely noted to impact public acceptance. Generally, acceptance is higher when human contact with water is minimal (Hartley, 2003). Application for industrial use therefore tends to be well accepted, but domestic use not (particularly drinking) (Po et al., 2003). A survey by Dolnicar et al. (2011) in Australia confirmed this $-92 \%$ of respondents confirming they would irrigate their gardens with recycled water, but only $36 \%$ would drink it.

\section{Health}

Health is a primary concern for all proposed applications of treated water. Public acceptance is higher when perceptions of its quality are good and clear health protection efforts are in place (Hartley, 2003). A number of reports note, however, that perceptions of quality are often based upon properties such as cloudiness or turbidity, not official guidance (Jeffry, 2002). A survey by Sydney Water (1999) found that 59\% of respondents regarding a reuse scheme agreed with the statement 'no one can guarantee the safety of recycled water'.

\section{Environmental benefits}

Public attitudes towards the environment impact their acceptance of water reuse, but often as a lower priority (Po et al., 2003). Public acceptance is higher when there are clear environmental and water conservation benefits (Hartley, 2003). This correlates with awareness and understanding of environmental issues, with higher acceptance in locations where water scarcity issues are widely acknowledged (Dolnicar et al 2011; Hartley, 2003; Po et al., 2003).

\section{Cost}

Predictably, public acceptance of water reuse is higher when costs of network installation and running are reasonable (Hartley, 2003). This relates to the concept of 'willingness to pay' (WTP), the upper charge people accept for reused water (Woolston and Jaffer, 2005). WTP is complex and assessments of it are contradictory. It relates to factors such as the value attached to reused water, people's attitudes towards it, and the potential for return on investment (Woolston and Jaffer, 2005).

\section{Trust}

Public trust in local authorities and technology is widely noted as influential over the acceptance of reuse (Syme and Williams, 1993; Hartley, 2003). Trust is in decline, particularly belief that even the best technologies can remove all health risks (Lawrence, 2000). Hurlimann (2007) furthers this to consider the impact past public experience with water reuse can have on acceptance, with awareness of failed schemes nearby often impeding positivity towards a new proposal. Finally, trust also relates to issues of equity and justice, with objections arising in San Diego in the 1990s on the basis that the recipients of recycled water were predominantly those in lower income communities (Shipps, 2013). 


\section{Socio-demographics}

Socio-demographic factors receive much attention regarding acceptance of water reuse, and caution must be taken in generalising the influence of demographic factors across different populations (Po et al., 2003). Dolnicar and Hurliman (2010) provide a comprehensive review of previous studies that show that acceptability is higher for men and those with higher levels of education. The age of respondents has been correlated to acceptability in different studies, though it has been positive and negative in different contexts (McKay and Hurliman, 2003; Dolnicar and Hurlimann, 2010; Dolnicar et al., 2011). Studies in the United States have shown that opposition comes from long-term residents (Robinson et al, 2005) and those on lower income (Hartley, 2003). In the United Kingdom, Jeffrey (2002) states there is no significant relationship between acceptance of water reuse and socio-demographics.

\section{International studies of public acceptability}

Much of the pioneering work on the public acceptance of reuse comes from Bruvold (1972; Bruvold et al., 1981), who examined public acceptance of potable and non-potable reuse in the 1970s and 1980s. Many recent studies, such as Marks (2006), are based on this work. Indeed, Bruvold suggested in 1972 that if opposition was higher than 50\%, implementation would be extremely problematic. This has been the case in both the United States and Australia (Marks, 2006).

Table 1 summarises public acceptability surveys, showing the percentage of acceptance of recycled water for drinking, cooking and aquifer recharge. This also gives an indication of the distribution of surveys, with the majority conducted in the United States and Australia.

Table 1: International surveys of public acceptability of indirect potable reuse

\begin{tabular}{|c|c|c|c|c|c|c|}
\hline & & & $\begin{array}{r}\% \mathrm{Su}_{\mathbf{I}} \\
\text { vari }\end{array}$ & $\begin{array}{l}\text { port for re } \\
\text { us applica }\end{array}$ & $\begin{array}{l}\text { use for } \\
\text { tions }\end{array}$ & \\
\hline Location & Year & $\begin{array}{l}\text { Sample } \\
\text { Size }\end{array}$ & Drinking & Cooking & $\begin{array}{l}\text { Aquifer } \\
\text { Recharge }\end{array}$ & Reference \\
\hline USA & 2005 & 303 & & & 15 & $\begin{array}{l}\text { Robinson et } \\
\text { al., 2005 }\end{array}$ \\
\hline USA - San Diego & 1993 & & 59 & & & Marks, 2006 \\
\hline USA - Tampa & 1996 & & 42 & & & Marks, 2006 \\
\hline Australia & 2005 & & 11 & 15 & & $\begin{array}{l}\text { Dolnicar and } \\
\text { Schafer, } 2009\end{array}$ \\
\hline & 2005 & 2,504 & 41 & 54 & & $\begin{array}{l}\text { Marks et al., } \\
2006\end{array}$ \\
\hline Australia - Sydney & 1999 & 1,300 & 26 & 34 & & $\begin{array}{l}\text { Marks et al., } \\
2006\end{array}$ \\
\hline & 1996 & 1,000 & 27 & 33 & & $\begin{array}{l}\text { Marks et al., } \\
2006\end{array}$ \\
\hline Australia - Perth & 2004 & 400 & 31 & & & Po et al., 2005 \\
\hline & 1999 & 666 & 16 & & & $\begin{array}{l}\text { Marks et al., } \\
2006\end{array}$ \\
\hline Israel - Haifa & 2006 & 256 & & & 11 & $\begin{array}{l}\text { Friedler et al., } \\
2006\end{array}$ \\
\hline
\end{tabular}


Robinson et al. (2005) report the results of a telephone survey in the United States examining wastewater reuse perceptions, knowledge and information sources. The study supported general trends for decreasing support with increasing levels of contact. Potable reuse was generally not acceptable, but the survey showed high acceptability for low personal contact applications such as fire fighting and lawn irrigation. Women were less in favour of potable reuse than men, although there was no variability by age or income. Overall opposition to potable uses was $78 \%$ (surface and ground water augmentation), with less than $20 \%$ agreeing.

Marks et al. (2006) summarise three Australian and three United States surveys of public acceptability in separate communities, undertaken between 1999 and 2002, and provide new data from a national telephone survey in Australia $(n=2504)$. Results showed that $42 \%$ of Australians were confident about using indirect potable reuse for drinking purposes. This research also confirmed the trend of acceptability decreasing as contact with reuse water becomes more personal. Similar to the United States findings, the Australian surveys showed reuse is more acceptable if it is the cheapest option.

Dolnicar and Schafer (2009) explored the public acceptability of both reuse and desalination water technologies in Australia, and the public's general understanding around these. In this study desalination was found to be almost as undesirable as reuse for many factors. For example, $11 \%$ of people thought they would drink recycled water, while desalination gained a surprisingly low 30\%. Many misunderstandings were identified, such as $24 \%$ of people thinking desalination water was 'recycled sewage' (compared with $70 \%$ for reuse). Overall Australians had fewer concerns about the health risks of desalination, but thought indirect potable reuse was more environmentally friendly.

Friedler et al. (2006) surveyed 256 participants in Israel regarding both potable and nonpotable reuse. An overwhelming majority supported wastewater reuse in general, but the results confirm the trend of decreasing support as contact with the recycled water increases. Only $11 \%$ of those surveyed supported indirect potable reuse via aquifer recharge, with $79 \%$ opposed. Acceptability was independent of age, gender, education and income.

\section{Methodology}

The Thames Water survey was designed to identify the overall level of acceptability of indirect potable reuse to its customers, to identify demographic factors that correlate with acceptability and to allow comparison with international studies. An on-line polling organisation was commissioned to deliver the survey to 2,000 Thames Water drinking water customers, split evenly between London and the Thames Valley region (the two geographical areas by which Thames Water is organised). The Thames Valley includes customers in smaller towns and cities in the River Thames catchment, outside London.

The survey was part of a feasibility study of potable reuse in London. It was necessary to include Thames Valley customers, who at this stage are not proposed to receive reused water, because as customers of Thames Water their bills reflect the overall cost of water supplied to all customers and therefore the acceptability of the proposal to all customers is an important consideration in the feasibility of any particular scheme. The population for the survey is therefore Thames Water customers, with two samples of 1,000 of London and Thames Valley customers. The sample is not intended to represent the English or British population as a whole, but results may be indicative of the wider context. Compared to the rest of the United Kingdom, Thames Water customers are on average younger, wealthier more highly educated 
and more likely to be immigrants, although considerable diversity exists within the population (Mateos, 2013).

The sample was drawn from existing panels constituted by the polling organisation and was broadly representative of the population of residents in the region, as shown in Table 2 . The polling organisation used stratified sampling to meet the required sample size with reasonable representation of the target population in terms of age, gender and socio-economic group. The use of existing panels, recruited and paid by the polling organisation to respond to onsurveys on a range of issues, allows for higher response rates and better stratification of the sample compared with alternative recruitment methods.

Overall, the survey sample contained more women than the population and more people in the middle-age groups, with a higher overall average age. Based on previous studies in other countries, women are less likely to accept potable reuse (Dolnicar et al,, 2011), whilst age has not been shown to have a consistent influence on acceptability, with different studies showing conflicting results (Hurlimann, 2007; Dolnicar and Schafer, 2009). The analysis of the data included testing of the significance of demographic variables within this sample, which did not indicate that any bias in the overall results arising from the skewed age and gender profile of the sample.

The on-line delivery of the survey had the advantages of allowing fast and easy distribution and analysis, a high response rate, improved representativeness and a potential reduction in response effects. The disadvantages of the on-line delivery include the potential sample bias towards those willing and able to access the internet, the potential for respondents to rush through the questions and limited opportunity to explain important concepts. 
Table 1: Socio-Demographic Information - comparison of survey and census data

\begin{tabular}{|c|c|c|c|c|}
\hline \multirow{2}{*}{ Demographic Factor } & \multicolumn{2}{|c|}{ London } & \multicolumn{2}{|c|}{ Thames Valley } \\
\hline & $\begin{array}{c}\text { Census } \\
(\%)\end{array}$ & $\begin{array}{c}\text { Survey } \\
(\%)\end{array}$ & $\begin{array}{c}\text { Census } \\
(\%)\end{array}$ & $\begin{array}{c}\text { Survey } \\
(\%)\end{array}$ \\
\hline \multicolumn{5}{|l|}{ Gender } \\
\hline - Male & 48.4 & 37.3 & 49.5 & 38.7 \\
\hline - Female & 51.2 & 61.9 & 50.5 & 60.8 \\
\hline - Refused & & 0.8 & & 0.5 \\
\hline \multicolumn{5}{|l|}{ Age } \\
\hline - 18 to 24 years & 12.6 & 7.3 & 11.7 & 9.1 \\
\hline - 25 to 44 years & 46.6 & 44.9 & 39.1 & 45.1 \\
\hline - 45 to 59 years & 20.3 & 30.3 & 24.3 & 30 \\
\hline - 60 to 64 years & 5.0 & 8.3 & 5.9 & 8.1 \\
\hline - 65 to 74 years & 8.2 & 6.6 & 10.0 & 5.6 \\
\hline - $75+$ years & 7.4 & 1.5 & 9.0 & 1.3 \\
\hline Average age (mid point) & 42.9 & 44.1 & 45.2 & 42.8 \\
\hline \multicolumn{5}{|l|}{ Socio-Economic Group } \\
\hline - Class ABC1 & 60.1 & 65.8 & 57.9 & 64.9 \\
\hline - Class C2DE & 39.9 & 28.6 & 42.1 & 29 \\
\hline - Refused to say & & 5.6 & & 6.1 \\
\hline
\end{tabular}

The survey began by providing information about unplanned and planned indirect potable reuse followed by a series of open and closed questions. The survey consisted of 18 questions relating to the level of support, risks and benefits of indirect potable reuse, and 6 questions relating to specific demographic factors (water meter present, have young children, belief system, household income, highest level of education, and, ethnicity) in addition to those provided as part of the normal survey panel data (location, gender, age, socio-economic group). Potentially sensitive topics such as income, ethnicity and religion included opt-out responses, to avoid non responses and gauge sensitivity of the questions asked. 
The questions, with possible responses in brackets, were:

1. Have you heard of 'Planned Reuse' before? (Yes, No, Don't know)

2. How supportive are you of 'Planned Reuse'? (Choice of 5 responses; 1 completely against - 5 completely supportive)

3. How confident are you that the water companies would be able to supply safe drinking water in this way? (Choice of 5 responses; 1 very confident - 5 not at all confident)

4. Do you drink water straight from the tap? (Yes direct from the tap, No filter it first, No don't drink tap water, Don't know)

5. Would you drink water straight from the tap with 'Planned Reuse'(Yes direct from the tap, No filter it first, No would not drink tap water, Don't know)

6. Who is your water supplier? (Open answer, Don't know)

7. Does your water supplier already use 'Unplanned Reuse'? (Yes, No, Don't know)

8. Does your water supplier already use 'Planned Reuse'? (Yes, No, Don't know)

9. Please explain the reasons for your answers to question 7 and 8 (Open answer)

10. How much do you trust Government agencies, and Scientists and Engineers in general, to manage a 'Planned Reuse' scheme? (Choice of 5 responses; 1 completely distrust - 5 completely trust)

1. Drinking Water Inspectorate

2. Scientists and Engineers

3. Environment Agency

4. Department of Health

5. Ofwat (the economic regulator)

6. Your local water company

11. Do you think there are any potential benefits of 'Planned Reuse'? (Yes, No, Don't know)

12. What are the benefits? (Open answer)

13. Do you think there are any risks of 'Planned Reuse' (Open answer)

14. What are the risks? (Open answer)

15. How would you best compare the risks versus the benefits of 'Planned Reuse' (Choice of 5 responses; 1 Benefits greatly outweigh risks - 5 Risks greatly outweigh benefits)

16. Please rate you level of agreement or disagreement with all the following statements (Likert Scale; 1 strongly agree - 5 strongly disagree)

- Water experts, such as scientists and regulators, should have control over the kind of water the community is supplied with'

- The general public should be consulted about using 'Planned Reuse' to supply water to houses in the UK

17. Rank the following options for 'Planned Reuse' according to your preference (Diagrams and explanation of environmental return options - river, reservoir, aquifer; rank 1 most preferred -3 least preferred)

18. What are the reasons for your ranking (Open answer).

The results of the survey questions in relation to levels of support and the risks and benefits of indirect potable reuse were analysed using the statistical package SPSS to determine the significance of any difference between demographic groups. Both parametric (t-tests) and non-parametric (Chi-Squared and Analysis of Variance, and Kruskal-Wallis) tests were used where appropriate to analyse the data. For example, where comparisons were made between variable factors, such as the location of London versus Thames Valley, with response scales, t-tests were used, whereas to compare demographics with question responses, Analysis of Variance was used. With the exception of religion, no statistical difference was found between demographic groups. Only the results giving an overall indication of the response of 
the sample as a whole or showing statistical significance between categories are reported in this paper.

This survey was one element of the social research component of the feasibility study of indirect potable reuse undertaken by Thames Water 2006-2011. The social research programme also included a deliberative research forum, which aimed to investigate the public response to indirect potable reuse in more detail and in relation to other water management issues in the South East of England. The deliberative forum involved 38 members of the public, who were broadly indicative of the general population. Before the forum they were provided with basic information about potable water reuse and were given time to make their own investigations on the topic, including discussions with family and friends. The main forum event was held over one day, and involved a series of facilitated discussions and activities, where participants were able to ask questions of experts, discuss the issues amongst themselves, and decide on their level of support for the proposal. The results of the deliberative research are not reported here, but are used to support the discussion of the survey results, and provided useful data for the overall feasibility study.

\section{Results}

The overall level of support for 'planned reuse' was $60 \%$ in response to the question 'how supportive are you of 'Planned Reuse'?', with only $12 \%$ of respondents either against or completely against 'planned reuse' (Figure 1).

\section{Q2: How supportive are you of using Planned Reuse to supply water?}

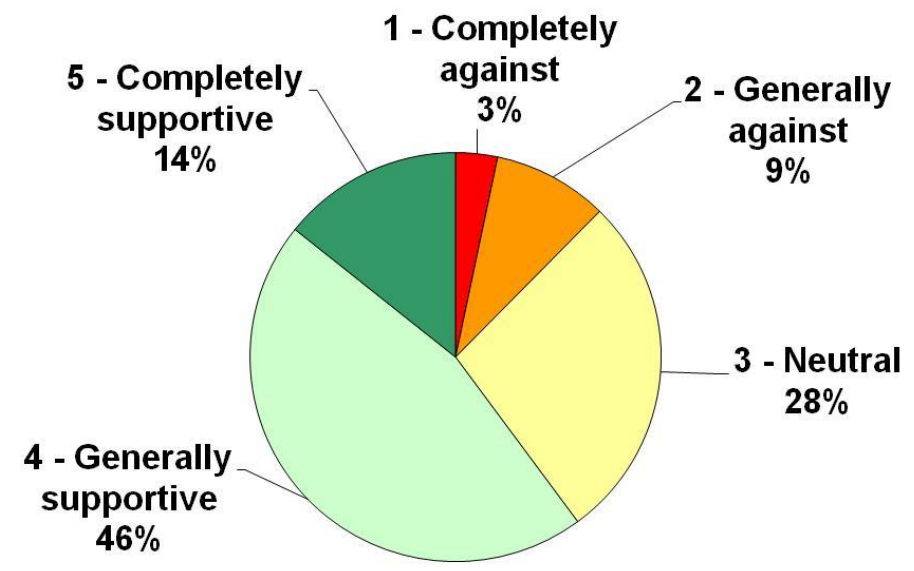

Figure 1: Survey results of support for planned reuse

Confidence in water companies to deliver indirect potable reuse safely was also reasonably high, with $61 \%$ of the sample either very confident or fairly confident, while $33 \%$ were either not very or not at all confident.

Levels of general support for planned reuse showed no significant difference between demographic categories of gender, age, socio-economic group, location in London or the Thames Valley, having children, or having a water meter. Differences were seen in ethnic and religious groups. People who selected the 'black' ethnic category or 'Islam' religious 
category were less supportive of 'planned reuse' than the sample overall, however of all the demographic categories only the 'Islam' group was statistically different, using Analysis of Variance, with a mean response of 2.8 , which is below the neutral rank of 3 out of 5 .

The survey included a description of unplanned indirect potable reuse, as distinct from planned indirect potable reuse. Of the respondents $21 \%$ said that their water supplier already uses unplanned reuse, $14 \%$ said that their supplier did not, but $65 \%$ didn't know.

Overall the respondents thought that the benefits associated with 'planned reuse' outweighed the risks, with $67 \%$ of respondents agreeing that there are potential benefits in using 'planned reuse' but only $7 \%$ thinking there were no benefits, and the remainder didn't know. The benefits listed in response to an open question included a sustainable and constant water supply, reduction in costs, and helping the environment. In relation to risks, $49 \%$ thought that there are potential risks associated with 'planned reuse', $18 \%$ saw no risks and $33 \%$ did not know if there were any risks. The risks listed were associated with contamination and health, accidents (despite the highest levels of technology and monitoring), and water companies aiming for minimum standards despite risks to some users. Overall $51 \%$ of the respondents thought that the benefits outweighed the risks, while 17\% thought that the risks outweighed the benefits, and the remaining $32 \%$ thought benefits and risks were equal.

Respondents were also asked whether they drink tap water now, and whether they expected to continue this if indirect potable reuse was introduced. While $9 \%$ said they did not currently drink tap water, this only increased to $12 \%$ with an indirect potable reuse supply. Bigger shifts were seen in those that do now drink tap water, with the $68 \%$ currently drinking water straight from the tap decreasing to $35 \%$ with indirect potable reuse. In addition, the $23 \%$ of respondents who currently treat tap water in some way before drinking it (for example, home filtering) increased to $40 \%$ if indirect potable reuse was the source. However, $75 \%$ still thought they would drink tap water in some form. The 'don't know' group shifted from less than $1 \%$ to $13 \%$ with an indirect potable reuse supply.

The Thames Water feasibility study includes investigation of three options for the return of reclaimed water from treated wastewater to augment drinking water supplies: return via the river, reservoir or aquifer. Aquifer return had the highest proportion of first preferences, with $47 \%$ listing this as their first preference (figure 2). While river and reservoir received similar first preferences at $26 \%$ and $27 \%$ respectively, river return was the clear least-favoured option, with 53\% ranking it third. River also received the lowest mean ranking of 2.3 (out of first, second and third preferences). Aquifer and reservoir mean rankings were equal at 1.9 out of 3 each.

Reasons for the preference of aquifer recharge include a perception of additional filtering provided by ground and water conservation compared to reservoir recharge due to reduced evaporation. Discharge to a reservoir was favoured because it provided better control of water quality and potential environmental impacts. River flow augmentation was not favoured because for concerns about pollution, both positive and negative, with some people concerned not to pollute the river, while others were concerned about contaminating the treated wastewater prior to treatment. There was also a misperception that treated wastewater discharged to the river is 'lost' to the sea. 


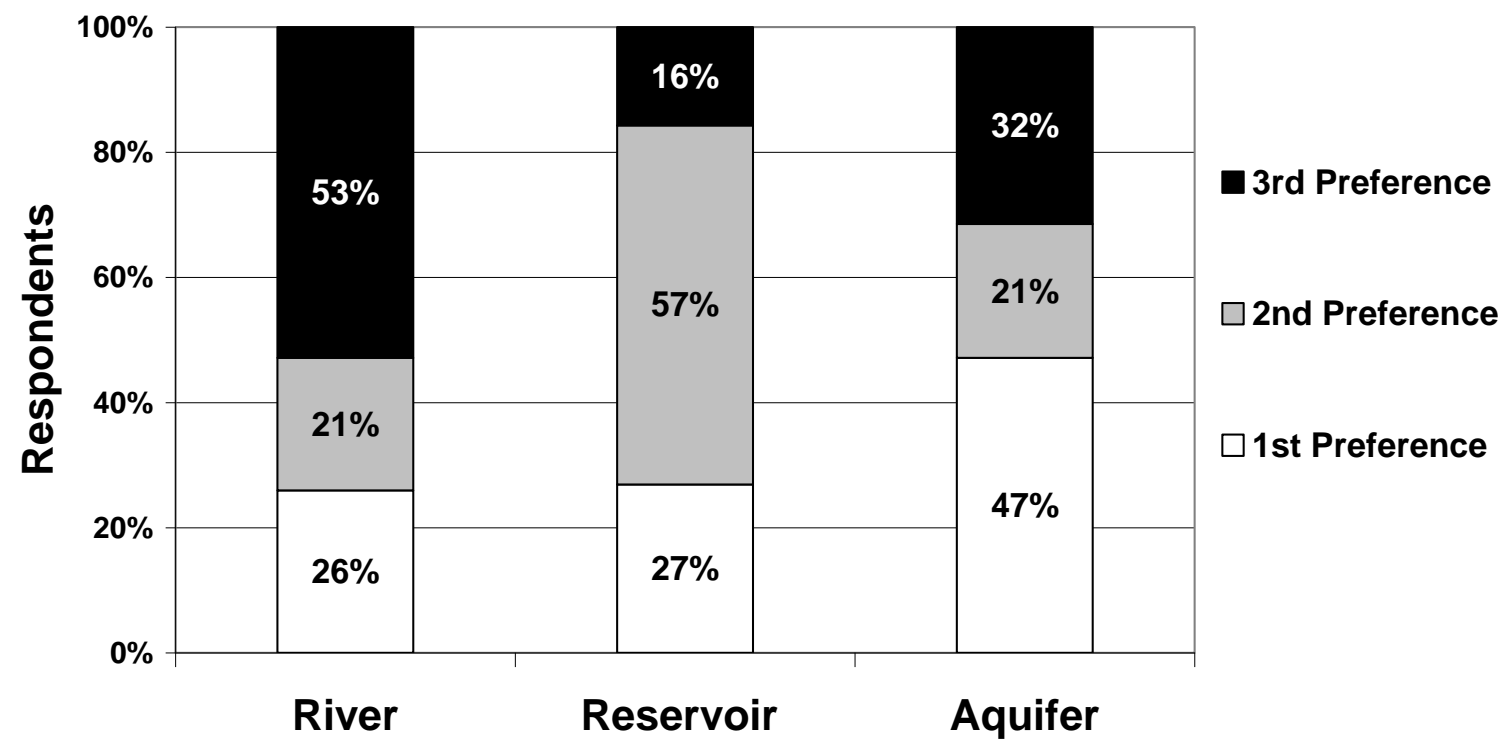

Figure 2: Environmental return preferences for reclaimed water

Although trust in authorities to manage planned reuse showed a similar overall pattern to studies by CSIRO in Perth (Po et al., 2004), with trust highest in scientists and engineers, followed in order by the Environment Agency, the economic regulator Ofwat, the Drinking Water Inspectorate, the Department of Health and the local water company lowest, the range of scores was much less in the Thames Water study, indicating less polarised views. The latter results were all within a tight range around the neutral value, with 3.3 the highest and 2.8 out of 5 lowest in contrast to the CSIRO results, which showed a two-fold difference between 'CSIRO scientists' (4) and 'private companies' (2.1). Respondents generally agreed with the statement that 'Water experts, such as scientists and regulators, should have control over the kind of water the community is supplied with', but importantly, agreement was higher for the statement 'The general public should be consulted about using Planned Reuse to supply water to houses in the UK'. Whilst trust in experts remains positive, there is increasing interest in the public being informed and involved in decision making about water resources in the United Kingdom.

Finally, the distributions seen across the wide range of data were generally bell shaped, although often with skewing. This observation is not meant to be of statistical significance, but rather to indicate that of all the topics investigated, none showed extreme polarisation of responses.

\section{Discussion}

From this survey it appears that support for indirect potable reuse may be higher in the southeast of the United Kingdom than in other countries. However, it is important to note that this survey positioned planned indirect potable reuse in the context of unplanned indirect potable reuse, rather than in comparison to non-potable reuse options. The lack of polarisation in the responses indicates that indirect potable reuse is currently not a divisive issue amongst the population surveyed and appears not to be as controversial a proposition in the United Kingdom as in other parts of the world. This may be because of the urbanised nature of the Thames catchment compared with Australia and the United States, leading to local experience and acceptance of unplanned reuse, with $21 \%$ if respondents indicating that their 
supplier used unplanned reuse. Qualitative results from the deliberative forum confirmed that participants already believed that unplanned reuse occurred, and planned reuse was thought to be preferable due to the higher levels of treatment of the wastewater before discharge and recycling.

The preference for aquifer recharge and reservoir supply over river flow augmentation as the means to introduce the treated wastewater into the drinking water system may also be related to the current experience of unplanned reuse. Aquifer recharge was thought to give the opportunity for further purification of the treated wastewater, while river discharge was associated with contamination. In the deliberative forums participants were unexpectedly favourable towards direct potable reuse, reasoning that treated waste water should not be further contaminated with raw water in the environment or reservoir. On the other hand, participants who were concerned about potential environmental impacts of water reuse were also likely to favour reservoir supplementation, to avoid potential pollution of rivers and aquifers.

The results for this study area (London and the Thames Valley) show no significant differences in support between genders, age, socio-economic status and other conventional demographic categories. Whilst this contrasts with some studies in Australia and the United States that have found significant differences relating to gender and income (see Dolnicar and Hurlimann, 2010) it confirms the specificity of public acceptability to particular populations, indicating the importance of wider cultural and social context in determining the feasibility of potable reuse and guiding public engagement strategies.

The level of support for indirect potable reuse is not universal, and Muslim respondents in particular showed significant concerns. This result is unique to this study, and has not been observed elsewhere. Dolnicar et al. (2011) found that belonging to a religion was negatively correlated to likelihood to use recycled water, but did not investigate specific religious affiliation. Prathapara et al. (2006) found that religion was cited as a reason for opposition to greywater reuse in Oman, despite religious teachings that permit water reuse. Water is of particular significance in Islamic practice because it is central to ritual ablutions, which may provide some explanation as to why Muslim respondents were more concerned about potable reuse than the wider population. The significance of water to London's Muslim population has been recognised in water conservation programmes delivered through mosques and community groups with high Muslim adherence, which may provide a useful basis for further exploring the attitudes of this group towards water reuse.

The level of trust in water companies compared to government agencies in London and the Thames Valley also contrasts with findings in Australia. Dolnicar and Hurliman (2010) found that Australians rated water authorities as a more influential source of information about water reuse than government agencies, while in this survey water companies were rated as the least trust worthy to deliver water reuse schemes compared to a number of relevant government bodies. This may be linked to the fully privatised nature of the water sector in the United Kingdom and is consistent with Bell's (2007) study of media representation of drought in Sydney and London. Newspaper reporting of drought in London in 2005 was highly critical of the private owners of Thames Water, whilst in Sydney drought was reported as a natural event with no criticism of the state owned Sydney Water.

The survey results were complemented by the results of the deliberative forum. The survey results provide a snap-shot indication of the general level of support for the idea of indirect 
potable water reuse. The deliberative forum provided an indication of the impact on public acceptability of more considered discussion about the topic, including the provision of information by experts. The deliberative research results will be reported in future publications, but in brief showed similar levels of support for the indirect potable reuse, which increased throughout the event as participants were able to discuss the issues and learn more about the proposal. However, the deliberative forums showed that support for water reuse is contingent upon public trust in the water company and perception of their performance. This is particularly important as the water companies are fully privatised, and the British public is aware that companies exist to make profit as much as to provide safe water. Sound management and good customer relationships in general are important in dealing with specific, potentially controversial issues like water reuse. Several participants expressed concern that Thames Water should address issues such as leakage and costs, as a higher priority than water reuse. This is consistent with survey results showing the relatively low levels of trust in water companies to provide safe drinking water using planned reuse.

\section{Conclusions}

The survey showed a strong baseline of support for indirect potable reuse in London and the Thames Valley, however the strong agreement from respondents about the need for public participation in decision making about indirect potable reuse shows that this support should not be taken for granted in the implementation of a future indirect potable reuse scheme. The results of this survey indicate baseline levels of public acceptance of indirect potable reuse, and do not relate to a specific proposal for indirect potable reuse in the Thames region. Any future decision to proceed with indirect potable reuse in the region will be dependent on a range issues as detailed in the company's Water Resources Management Plan. Obviously decisions would also need to consider more specific social research on the proposal and incorporate a public deliberation and engagement programme (Bell and Aitken, 2008; Russell et al., 2008). It is possible that support for a specific proposal for indirect potable reuse in London will be lower than the support for the general concept that was found in this study.

The survey results provide an indication of general support for the idea of potable reuse, but do not guarantee public approval of a specific proposal for indirect potable reuse in London or the Thames Valley. The findings of this survey and international experience indicate that a public engagement strategy for implementation of potable water reuse in London will need to account for concerns specific to the Muslim population and will need to build trust between the water company and the public. Communication about water reuse may best delivered by government agencies and independent scientists and engineers. Continued engagement with the public and attention to the concerns and experiences of particular segments of the population will be needed to ensure effective decision-making and delivery.

\section{Acknowldegements}

This work was funded by Thames Water and the UK Engineering and Physical Research Council.

\section{References}

Angelakis A. and Durham B. 2008. Water recycling and reuse in EUREAU countries: Trends and Challenges. Desalination: 218, 3-12.

Bell S. 2009. The driest continent and the greediest water company: newspaper reporting of drought in Sydney and London. International Journal of Environmental Studies: 66, 581-589. 
Bell S. and Aitken V. 2008. The socio-technology of indirect potable water reuse. Water Science and Technology: Water Supply, 8, 441-448 .

Bruvold W. H. 1972. Public attitudes towards reuse of reclaimed water. Contribution 137, Water Resource Centre, University of California, Berkeley, USA.

Bruvold W. H. 1985. Obtaining public support for reuse water. American Water Works Association Journal: 77, 72-77.

Bruvold W. H. 1988. Public opinion on water reuse options. Journal of the Water Pollution Control Federation: 60, 45-49.

Bruvold W. H. 1992. Public evaluation of municipal water reuse alternatives. Water Science and Technology: 26, 1537-1543.

Bruvold W. H., Olson B. H. and Rigby M. 1981. Public Policy for the Use of Reclaimed Water. Journal of Environmental Management, 5, 95-107.

Colebatch H.K., 2006. Governing the use of water: the institutional context. Desalination $187,1727$.

Dolnicar S. and Hurlimann A. 2010. Water alternatives - who and what influences public acceptance? Journal of Public Affairs; 11, 49-59.

Dolnicar S., Hurlimann A., and Grün B. 2011. What affects public acceptance of recycled and desalinated water? Water Research: 45, 933-943.

Dolnicar S., Hurlimann A. and Nghiem L.D. 2010. The effect of information on public acceptance - The case of water from alternative sources. Journal of Environmental Management: 91, 1288-1293.

Dolnicar S. and Schafer A. I. 2009. Desalinated versus recycled water: Public perceptions and profiles of the acceptors. Journal of Environmental Management, 90, 888-900.

Friedler E., Lahav O., Jizhaki H. and Lahav T. 2006. Study of urban population attitudes towards various wastewater reuse options: Israel as a case study. Journal of Environmental Management, 81, 360-370.

Hartley T. 2003. Water reuse: Understanding public perception and participation. Water Environment Research Federation, Alexandria, USA.

Hartley T. W. 2006. Public perception and participation in water reuse. Desalination, 187, $115-126$.

Hurlimann A. and Dolnicar S. 2010. When public opposition defeats alternative water projects - The case of Toowoomba Australia. Water Research: 44, 287-297.

Hurlimann A. 2007. Is recycled water use risks? An urban Australian community's perspective. The Environmentalist: 27, 83-94.

Ilemobade A., Adewumi J. and Van Zyl J. 2009. Framework for assessing the viability of implementing dual water reticulation systems in South Africa. Water SA: 35, 216-227.

Jeffry P. 2002. Understanding public receptivity issues regarding "in-house" water recycling. Results from a UK survey. Cranfield University, UK.

Lawrence G. 2000. Survey of Orange County voters within the Orange County Water District, Santa Ana CA. Lawrence Research- Public Affairs and Marketing. California.

McKay J. and Hurlimann A. 2003. Attributes to reclaimed water for domestic use: Part 1. Water Journal of the Australian Water Association: Hurlimann Apor, 45-49.

Marks J.S. 2006. Taking the public seriously: The case of potable and non potable reuse. Desalination, 187, 137-147.

Marks J.S., Martin, B. and Zadoroznyj, M. 2006. Acceptance of water recycling in Australia: National baseline data. Water, 33, 151-157.

Mateos P. London's population. In Imagining the Future City: London 2062. Ubiquity Press. London. 
Po M., Kaercher J. D. and Nancarrow B. E. 2004. Literature Review of Factors Influencing Public Perceptions of Water Reuse. Report CSIRO Land and Water, and Australian Water Conservation and Reuse Research Program, Perth, Australia.

Prathapara S., Jamrahb A., Ahmeda M., Al Adawia S., Al Sidairia S. and Al Harassib A. 2006. Overcoming constraints in treated greywater reuse in Oman. Desalination, 186, 177-186.

Robinson K. G., Robinson C. H. and Hawkins S. A. 2005. Assessment of public perception regarding wastewater reuse. Water Science and Technology: Water Supply, 5, 59-65.

Russell S., Lux C. and Hampton G. 2008. Beyond 'Information': Integrating Consultation and Education for Water Recycling Initiatives, Society and Natural Resources, 22, 5665.

Shipps H. 2013. Water reuse as part of San Diego's water portfolio. Scripps Senior Thesis, Paper 144. [URL] Available at: http://scholarship.claremont.edu/scripps_theses/144 (accessed 12.6.13).

Sydney Water 1999. Community views on recycled water. Sydney Water Corporation, New South Wales, Australia.

Syme G., Nancarrow B., Stevens D., Kelly J., McLaughlin M. and Unkovich M. 2006. Social psychological considerations in the acceptance of reclaimed water for horticultural irrigation. CSIRO, Australia.

Syme G. and Williams K. 1993. The psychology of drinking water quality: an exploratory study. The Journal of Water Resources Research: 29, 4003-4010.

Thames Water Utilities Limited 2013. Draft Water Resources Management Plan 2015-2040, May 2013. Thames Water Utilities Limited, Reading, United Kingdom.

Water Resources in the South East Group 2013. Progress towards a shared water resources strategy for the South East of England, Phase 2b Report February 2013.

Woolston M. and Jaffer S. 2005. Pricing of Water. Occasional Paper No.1. Water Services Association of Australia, Melbourne. 